Научная статья

УДК 338.246

DOI https://doi.org/10.24866/VVSU/2073-3984/2021-3/053-061

\title{
М.С. Рахманова
}

Владивостокский государственный университет экономики и сервиса

Владивосток. Россия

\section{Проблемы развития малого и среднего предпринимательства в Российской Федерации}

В Российской Федерации развитию малого и среднего предпринимательства придается большое значение, так как субъекты малого и среднего предпринимательства, несомненно, играют большую роль в экономике нашей страны, ведь благодаря их четким и целенаправленным действиям создаются рабочие места, внедряются новые технологии, в то же время обязательно учитываются особенности территории с целью реализации своей деятельности именно там, где возможно получить максимальный экономический эффект. Однако новые вызовы внешней среды могут негативно сказываться на деятельности субъектов малого и среднего предпринимательства. В первую очередь, сектор малого и среднего предпринимательства пострадал в период коронавирусной пандемии ввиду возникшего экономического кризиса, закрытия как внешних, так и внутренних рынков. Кроме того, существующие административные и экономические проблемы препятствуют развитию субъектов малого и среднего предпринимательства, а иногда вообще приводят к их банкротству. В статье проведен краткий анализ состояния субъектов малого и среднего предпринимательства в России, анализ основных экономических показателей их деятельности. Показано, что на современном этапе продолжают оставаться нерешенными проблемы, препятствующие полноценному развитию субъектов малого и среднего предпринимательства. Понимание перспектив и тенденций развития малого бизнеса, а также решение проблем, ограничивающих их развитие, имеют важное значение.

Ключевые слова и словосочетания: субъекты малого и среднего предпринимательства, экономические показатели деятельности, индивидуальные предприниматели, проблемы субъектов малого и среднего предпринимательства.

Рахманова Марина Сергеевна - канд. экон. наук, доцент, доцент Института экономики и управления, руководитель Центра научных исследований, проектов и программ; e-mail: Marina.Rakhmanova@vvsu.ru 


\section{M.S. Rakhmanova}

Vladivostok State University of Economics and Service

Vladivostok. Russia

\section{Problems of development of small and medium-sized businesses in the Russian Federation}

In the Russian Federation, the development of small and medium-sized businesses is given great importance, since small and medium-sized businesses undoubtedly play an important role in the economy of our country, because thanks to their clear and purposeful actions, jobs are created, new technologies are introduced, with all this, the peculiarities of the territory are necessarily taken into account in order to implement their activities in those territorial areas that will bring a significant part of income. However, new challenges of the external environment can negatively affect the activities of small and medium-sized businesses. First of all, the small and medium-sized business sector suffered against the background of the coronavirus pandemic, which resulted in the creation and impact of the economic crisis, the closure of both external and internal markets. In addition, there are a number of administrative and economic problems that negatively affect the development of small and medium-sized businesses, and sometimes even lead to their bankruptcy. The article provides a brief analysis of the state of small and medium-sized businesses in Russia, analyzes the main economic indicators of their activities, which showed that today there are still unresolved problems that hinder the full development of small and medium-sized businesses. Understanding the prospects and trends of small business development, as well as solving problems that limit their development, is important.

Keywords: small and medium-sized businesses, economic performance indicators, individual entrepreneurs, problems of small and medium-sized businesses.

\section{Введение}

За последние годы малое и среднее предпринимательство (далее - МСП) превратилось в один из важнейших секторов экономики. По данным главы Министерства экономического развития и торговли (МЭРТ) России, доля малого и среднего предпринимательства в ВВП России составила в 2018 году - 20,2\%, в 2019 году - не более 17\%, в то время как доля МСП в ВВП развитых стран составляет порядка 50\%, в Китае - более 60\% [1-3].

Согласно данным, представленным в едином реестре субъектов малого и среднего предпринимательства Федеральной налоговой службы на 10.08.2021 года, в России зарегистрировано 5620,99 тыс. субъектов МСП (табл. 1). 


\section{Экономические показатели деятельности субъектов МСП, включая микропредприятия}

\begin{tabular}{|l|l|l|l|l|l|}
\hline \multicolumn{2}{|c|}{ Показатели } & 2018 & 2019 & 2020 & 10.08 .2021 \\
\hline \multicolumn{7}{|c|}{ Данные по Российской Федерации } \\
\hline Число предприятий (на конец года), тыс. шт. & 6041,19 & 5916,90 & 5684,56 & 5620,99 \\
\hline $\begin{array}{l}\text { Среднесписочная численность работников, } \\
\text { тыс. чел. }\end{array}$ & 15873,59 & 15321,79 & 15491,14 & 14646,50 \\
\hline Оборот предприятий, млрд руб. & 4823,00 & 6081,00 & 8160,00 & 8627,00 \\
\hline \multicolumn{6}{|c|}{ Данные по Дальневосточному федеральному округу } \\
\hline Число предприятий (на конец года), тыс. шт. & 314,9 & 311,2 & 303,19 & 296,13 \\
\hline Данные по Приморскому краю & 88,4 & 84,8 & 81,9 \\
\hline
\end{tabular}

Примечание: таблица составлена по данным, представленным в едином реестре субъектов малого и среднего предпринимательства Федеральной налоговой службы на 10.08.2021. URL: https://ofd.nalog.ru/.

По сравнению с предыдущими периодами их количество сокращается. Аналогичная ситуация прослеживается и по Дальневосточному федеральному округу, и по Приморскому краю. Так, если сравнивать количество субъектов МСП с данными 2018 года, то по Российской Федерации их количество сократилось на $7 \%$, по Дальневосточному федеральному округу - на 6\% и по Приморскому краю - на 8,5\%.

Сокращение числа малых предприятий отразилось также на численности рабочих мест. Среднесписочная численность работников МСП Российской Федерации в 2018 году составила 15 873,6 тыс. человек против 14 646,5 тыс. человек в 2021 году. Снижение количества субъектов МСП явилось причиной снижения среднесписочной численности работников этих предприятий.

\section{Основная часть}

Тенденция снижения количества субъектов МСП обусловлена, прежде всего, такими первоочередными и важными тенденциями, которые негативно отразились на деятельности субъектов МСП, как противоэпидемиологические меры и усиление налогового контроля. Причем данные факторы начали свое действие примерно в одно время.

Масштаб пандемии COVID-19 создал трудные, а для многих секторов невозможные условия функционирования субъектов МСП. Данные меры повлекли за собой:

- закрытие внешних рынков, что для многих предприятий послужило причиной разорения и закрытия; 
- сокращение доходов населения, что повлекло за собой снижение спроса, а также сокращение предложения товаров и услуг вследствие их невостребованности;

- неопределенность экономики в целом и высокая степень турбулентности внешней среды, которая наблюдается на протяжении уже длительного периода, и, самое главное, не прослеживается четкая траектория перспективного развития по окончании пандемии.

Еще одна весьма важная тенденция сокращения числа субъектов МСП проявилась в усилении налогового контроля:

- внедрение онлайн-касс;

- повышение налога на добавленную стоимость с 18 до 20\%;

- борьба Федеральной налоговой службы с фирмами-однодневками;

- цифровизация бизнеса, заставившая многие субъекты МСП выйти из теневого сектора, в силу нежизнеспособности они вынуждены были уйти с рынка;

- легализация и официальное трудоустройство работников субъектов МСП [4].

Приведенные выше проблемы, препятствующие развитию МСП, являются первоочередными в современных тенденциях внешней среды и воздействуют абсолютно на все субъекты МСП, независимо от их территориальной принадлежности.

Тем не менее, существует достаточный перечь других проблем, препятствующих развитию МСП в целом, которые можно классифицировать на административные и экономические [5].

Административные проблемы - это проблемы, которые реализуются в качестве барьеров, установленных органами власти, чтобы предприниматели не смогли в полной мере реализовать свою непосредственную деятельность. Бизнес-субъект сталкивается с такими проблемами на всех стадиях своего жизненного цикла. Данные барьеры «преследуют» предпринимателей практически с момента их выхода на рынок.

Количество существующих барьеров постоянно увеличивается. Причинами тому служат разнообразные факторы.

Одним из барьеров является чиновничий бюрократизм. В настоящее время возросло количество чиновников, которые курируют различные виды управленческой деятельности. В связи с этим возникают трудности в согласовании тех или иных решений и обмене информацией в целом, так как количество принимающих решения существенно влияет на качество и конкретность принятых решений. А ведь именно от властных структур в большей мере зависит успешность решения.

Несовершенство законодательной базы проявляется в постоянстве изменений правил деятельности субъектов МСП. В нормативно-правовые акты несколько раз в год могут вноситься изменения относительно того, как субъектам МСП функционировать в различных жизненных ситуациях, что весьма затрудняет их предпринимательскую деятельность. Усугубляется ситуация еще и воздействием определенных человеческих факторов, исходя из которых иногда 
очень сложно или труднодоступно найти ту или иную измененную информацию. Сложно не только найти, но и применить, ведь на предприятии, например, может возникнуть нехватка каких-либо ресурсов для исполнения того или иного нововведенного закона.

Еще один административный барьер видится в несовершенстве налоговой базы. Налоговая политика несет в себе отрицательное воздействие на малый и средний бизнес в целом, так как в полной мере не является идеальной. Количество налоговых льгот превышает их качество.

Существующая статистика свидетельствует, что около 90-100\% балансовой прибыли предпринимателей изымается в федеральный, региональный и местный бюджеты. Поэтому предприниматели ищут различные способы, чтобы не платить налоги, например, ведут двойную бухгалтерию или уходят в теневой бизнес. Система налогообложения носит фискальный характер, который направлен на то, чтобы максимально изъять средства предприятий, полученные от их предпринимательской деятельности. Таким образом, предприниматели лишаются прибыли [6].

Система налогообложения представляет собой достаточно острую проблему для многих субъектов предпринимательства. Нехватка грамотно и доступно изложенного методического и инструктивного материала приводит к тому, что субъекты МСП получают большое количество налогов, обязательных платежей, сборов, а также пени и неустойки за несвоевременные оплаты или допущенные ошибки.

Существенная административная проблема видится в несовершенстве финансово-кредитной системы. Нецелевое использование бюджетных средств, отсутствие четкого порядка их использования привели к тому, что механизм финансово-кредитной системы не приносит должных результатов.

Ключевым фактором, ограничивающим инвестиционную деятельность субъектов МСП, является недостаток собственных финансовых средств. Данный фактор отмечают $49 \%$ субъектов МСП от общего количества организаций. Вторую по важности группу факторов, сдерживающих инвестиционную деятельность субъектов МСП, составляют высокие проценты по кредитам, предоставляемым коммерческими банками, низкий спрос на продукцию по причине снижения покупательной способности населения, высокая степень турбулентности и неопределенности экономической ситуации в стране.

Сложность и высокая стоимость регистрации предпринимательских структур - важная административная проблема. На территории Приморского края реализуется инновационный механизм в режиме «одно окно», но при этом отсутствует единый порядок государственной регистрации юридических лиц.

Действующая система лицензирования предпринимательской деятельности также препятствует развитию МСП. При вводе каких-либо ограничений для реализации предпринимательской деятельности данный факт сам по себе служит барьером для осуществления предпринимательской деятельности. Одним из таких ограничений является лицензирование, т.е. разрешение на выполнение каких-либо действий, которое может быть удостоверено каким-либо одноимен- 
ным документом. Отсутствие нормативно-правовых документов, устанавливающих порядок лицензирования, влечет несовершенство законодательства в сфере лицензирования.

К административным проблемам также относят избыточный контроль и надзор за предпринимательской деятельностью. Государственный контроль, несомненно, должен присутствовать во всех сферах деятельности в целях обеспечения нормального социально-экономического развития и экономической безопасности любой цивилизованной страны на основе баланса интересов потребителей (населения), хозяйствующих субъектов (предпринимателей) и государства, но такой контроль, прежде всего, должен быть разумным. В Российской Федерации контролирующая деятельность за малым и средним бизнесом занимает достаточно лидирующие позиции.

Данный факт объективно следует из результатов различных мониторингов в сфере МСП, а также исходя из жалоб и заявлений, написанных предпринимателями для того, чтобы защитить свои законные права и интересы.

Согласно данным Торгово-промышленной палаты Российской Федерации, в России функционируют 50 органов федеральной, региональной и местной власти, которые осуществляют контроль над деятельностью малого и среднего бизнеса.

Однако основная проблема не в том, что существует большое количество контролеров, а в том, что они работают независимо и их проверки не согласованы друг с другом по времени, месту и т.д. Цели и задачи контролирующих органов устанавливают различные нормативно-правовые акты, регламентирующие их деятельность. Контролирующие органы призваны предупреждать нарушения и защищать законные права и интересы граждан, однако многие из них нарушают законодательство и действуют в своих корыстных целях, что особо наблюдается в конце рабочих дней и в канун праздников. Подобные действия являются, прежде всего, противозаконными и неэффективными, так как они показывают, что система контроля как единое целое в Российской Федерации, направленное на благо каждого человека, общества и государства, отсутствует.

Экономические проблемы - это проблемы, связанные с возникновением различных неоправданных непроизводственных затрат при осуществлении предпринимательской деятельности либо с принудительным изъятием со стороны государства части доходов малого и среднего бизнеса, а также со сложностями для получения необходимых средств и материальных ресурсов для осуществления предпринимательской деятельности.

Экономические проблемы отражают трудности организации на различных этапах осуществления своей предпринимательской деятельности:

- на стадии организации предприятия - разработка пакета учредительных документов; сдача пакета документов на регистрацию; постановка на учет в налоговой инспекции; открытие расчетного счета в банке; получение лицензии на право осуществления деятельности и пр.; 
- на стадии старта деятельности организации - недостаток оборотных средств; нехватка производственных площадей; крайне высокая арендная плата и др.;

- на стадии становления и развития субъектов МСП - жесткая конкуренция на производственном рынке; бессистемный характер проверок со стороны контрольно-ревизионных структур [7].

Помимо вышеуказанных проблем возникают общие экономические сложности, мешающие осуществлению предпринимательской деятельности.

Так, монополистические действия естественных монополий, доминирующих на рынке, выражаются в необоснованных требованиях: естественные монополии, предоставляя какие-либо услуги, включают в договоры такие условия, которые дискриминируют права и действия малых предприятий, а также повышают стоимость на свои товары и предлагаемые услуги.

Далее следует отметить, что на любом рынке труда, помимо возможностей или условий, которые будут помогать в осуществлении предпринимательской деятельности, существуют угрозы, то есть те условия, которые могут препятствовать реализации и осуществлению предпринимательской деятельности:

- невыполнение потребителями продукции предприятия условий договора в части ее оплаты;

- невыполнение своих обязательств поставщиками;

- утечка информации из коммерческих банков.

Среди экономических проблем выделяют также ограниченный доступ предпринимателей к финансовым и материальным ресурсам. На сегодняшний день к особым правилам получения кредита относятся такие, которые регламентируют предоставление организацией объемного пакета документов, который будет включать в себя бизнес-план данной организации, устав, заверенную справку о регистрации, состав учредителей и т.д. Высокая стоимость финансово-кредитных ресурсов тоже является одним из серьезных препятствий для развития предпринимательства. Примерно реальная процентная ставка по кредитам для субъектов МСП составляет от 25 до 35\%. Но самое главное правило включает в себя предоставление кредита только под материальное обеспечение, то есть под залог, в качестве которого может выступать недвижимость, оборудование и иное высоколиквидное имущество. В свою очередь, все это имущество должно быть оформлено и документально подтверждено, а также как минимум должно вдвое превышать размеры самого кредита [7]. Поэтому реальные условия, для того чтобы система кредитования в нашей стране развивалась, не созданы, так как, например, в худшем случае организации на первоначальном этапе не находится какого-либо имущества, которое можно было бы оставить в качестве залога.

\section{Выводы}

Анализ состояния малых и средних предприятий позволяет сделать вывод, что, несмотря на существенные изменения внешней среды, неоднозначно влияющие на деятельность субъектов МСП, нестабильную экономическую ситуацию в стране, малые и средние предприятия имеют стимулы для своего развития. На фоне общего сокращения количества субъектов МСП как по Россий- 
ской Федерации в целом, так и по отдельным территориям в частности, а также численности работников повысился оборот малых и средних предприятий. Тем не менее, продолжают оставаться нерешенными проблемы, препятствующие полноценному развитию МСП. Понимание перспектив и тенденций развития малого и среднего бизнеса, а также решение проблем, ограничивающих его развитие, имеют важное значение для развития России, в частности, для развития стратегического потенциала региона.

Ряд серьезных проблем мешает развитию субъектов МСП, их решение должно, прежде всего, осуществляться на государственном уровне. Из-за существующих проблем владельцы субъектов МСП не заинтересованы в собственном развитии, а также в экономическом росте в целом. Получая денежные средства на реализацию своих предприятий, предприниматели расходуют их неэффективно, что ведет к утечке денежных средств из бюджета. Следовательно, денежные средства уходят, а проблемы развития МСП в Российской Федерации так и остаются нерешенными.

1. Заболоцкая В.В., Хут Н. А. Сравнительный анализ мер поддержки малого и среднего бизнеса в России и за рубежом. - Текст: электронный // Теория и практика общественного развития: социология, экономика, право: международный научный журнал: [сайт]. - URL: http://teoria-practica.ru/rus/files/arhiv_zhurnala/2015/10/ economics/zabolotskaya-khut.pdf (дата обращения: 02.09.2021).

2. Захарова Н. В., Лабудин А. В. Малое и среднее предпринимательство в европейских странах: основные тенденции развития // Управленческое консультирование. - 2017. № $12 .-$ C. 64-76.

3. Развитие малого и среднего предпринимательства. Сравнительный анализ российского и международного опыта // Аналитические материалы ОАО «МСП БАНК», 2014.

4. Земцов С.П., Царева Ю.В. Тенденции развития малых и средних предприятий в условиях пандемии и кризиса // Мониторинг экономической ситуации в России. Тенденции и вызовы социально-экономического развития. - 2020. - № 10. - С. 155-166.

5. Еваленко М. И. Потенциал малого и среднего предпринимательства и экономика российских регионов // Предприниматель. - 2016. - № 9. - С. 30-38.

6. Зотиков Н.3. Налогообложение малого бизнеса, его роль в доходах бюджетов - Текст: электронный // Вестник Европейской науки. - 2018. - № 1, T. 10. - URL: https://esj.today/PDF/30ECVN118.pdf (дата обращения: 02.09.2021).

7. Иванова Т.Б., Переверзев Н. А. Развитие теории жизненного цикла предприятий в современных условиях. - Текст: электронный // Научная электронная библиотека «КиберЛенинка». - URL: https://cyberleninka.ru/article/n/razvitie-teorii-zhiznennogo-tsiklapredpriyatiy-v-sovremennyh-usloviyah/viewer (дата обращения: 02.09.2021).

\section{References}

1. Zabolockaya V.V., Hut N. A. Sravnitel'nyj analiz mer podderzhki malogo i srednego biznesa v Rossii i za rubezhom. - Tekst: elektronnyj // Teoriya i praktika obshchest-vennogo razvitiya: sociologiya, ekonomika, pravo: mezhdunarodnyj nauchnyj zhurnal: [sajt]. URL: http://teoria-practica.ru/rus/files/arhiv_zhurnala/2015/10/ econom-ics/zabolotskayakhut.pdf (data obrashcheniya: 02.09.2021). 
2. Zaharova N. V., Labudin A. V. Maloe i srednee predprinimatel'stvo v evropejskih stranah: osnovnye tendencii razvitiya // Upravlencheskoe konsul'tirovanie. - 2017. - № 12. - S. 6476.

3. Razvitie malogo i srednego predprinimatel'stva. Sravnitel'nyj analiz rossijsko-go i mezhdunarodnogo opyta // Analiticheskie materialy OAO «MSP BANK», 2014.

4. Zemcov S. P., Careva Yu. V. Tendencii razvitiya malyh i srednih predpriyatij v usloviyah pandemii i krizisa // Monitoring ekonomicheskoj situacii v Rossii. Tendencii i vyzovy social'no-ekonomicheskogo razvitiya. - 2020. - № 10. - S. 155-166.

5. Evalenko M. I. Potencial malogo i srednego predprinimatel'stva i ekonomika rossijskih regionov // Predprinimatel'. - 2016. - № 9. - S. 30-38.

6. Zotikov N. Z. Nalogooblozhenie malogo biznesa, ego rol' v dohodah byudzhetov - Tekst: elektronnyj // Vestnik Evropejskoj nauki. - 2018. - № 1, T. 10. - URL: https://esj.today/PDF/30ECVN118.pdf (data obrashcheniya: 02.09.2021).

7. Ivanova T. B., Pereverzev N. A. Razvitie teorii zhiznennogo cikla predpriyatij v sovremennyh usloviyah. - Tekst: elektronnyj // Nauchnaya elektronnaya biblioteka «KiberLeninka». - URL: https://cyberleninka.ru/article/n/razvitie-teorii-zhiznennogotsikla-predpriyatiy-v-sovremennyh-usloviyah/viewer (data obrashcheniya: 02.09.2021).

(C) М.С. Рахманова, 2021

Для цитирования: Рахманова М.С. Проблемы развития малого и среднего предпринимательства в Российской Федерации // Территория новых возможностей. Вестник Владивостокского государственного университета экономики и сервиса. - 2021. T. 13, № 3. - C. 53-61.

For citation: Rakhmanova M. S. Problems of development of small and medium-sized businesses in the Russian Federation, The Territory of New Opportunities. The Herald of Vladivostok State University of Economics and Service, 2021, Vol. 13, № 3, pp. 53-61.

DOI https://doi.org/10.24866/VVSU/2073-3984/2021-3/053-061

Дата поступления: 25.08.2021. 